\title{
Nanocomposite Fibers Sensor
}

\author{
FlorinaRegius, P MastanVali, SidharthSuman, Shridduta Banerjee, \\ VarunVenkat \\ Nantechnology Research Center, SRM University, Chennai, T.N
}

\begin{abstract}
Nowadays, Electro-spinning has gained an increased attention towards gas sensing material, battery and solar cells. Among the other 1-D nanostructures, nano-fibers have an advantage of large surface to volume ratio, long axial ratio, large porosity and good mechanical properties. The metal oxides are extremely importanttechnological materials for use in electronic andphotonic devices. Electrospinning method is welldue to its easier performation and massproduction of fibers and variety of applications invarious fields. This paper describes about the sensing studies of zinc oxide and nickel oxide ( $\mathrm{ZnO}-\mathrm{NiO}$ ) nanocompositefibers prepared by electro-spinning method. Polyvinyl Alcohol (PVA) is used as a polymer to form fibers of ZnONiOnanocomposite which was deposited on the glass substrate at room temperature (RT). The basic characterization studies and gas sensing studies of as-spun fibers on formaldehyde and ammonia were studied.

Keywords: electrospining ,nanofibers, performation, PVA, formaldehyde, photonic , ammonia
\end{abstract}

\section{Gas Sensor-An Introduction:}

A gas sensor is a device which detects the presence of different gases in an area, especially those gases which might be harmful to humans or animals. The development of gas sensor technology has received considerable attention in recent years for monitoring environmental pollution. It is well known that chemical gas sensor performance features such as sensitivity, selectivity, time response, stability, durability, reproducibility, and reversibility are largely influenced by the properties of the sensing materials used. Many kinds of materials such as polymers, semiconductors, carbon graphites, and organic/inorganic composites have been used as sensing materials to detect the targeted gases based on various sensing techniques and principles. It is worth noting that the sensitivity of chemical gas sensors is strongly affected by the specific surface of sensing materials. A higher specific surface of a sensing material leads to a higher sensor sensitivity, therefore many techniques have been adopted to increase the specific surface of sensing films with fine structures, especially to form the nanostructures, taking advantage of the large specific surface of nanostructured materials.

\subsection{NANOFIBERS GAS SENSOR:}

Electrospunfibers with controllable membrane thickness, fine structures, diversity of materials, and large specific surface are expected to be an ideal candidate as the structure of sensing materials. So far, many attempts are carried out to prepare ultrasensitive gas sensors to detect vapors of $\mathrm{NH} 3, \mathrm{H} 2 \mathrm{~S}, \mathrm{CO}, \mathrm{NO} 2, \mathrm{O} 2, \mathrm{CO} 2$, moisture, and VOCs $(\mathrm{CH} 3 \mathrm{OH}, \mathrm{C} 2 \mathrm{H} 5 \mathrm{OH}, \mathrm{C} 5 \mathrm{H} 10 \mathrm{Cl} 2, \mathrm{C} 6 \mathrm{H} 5 \mathrm{CH} 3, \mathrm{C} 4 \mathrm{H} 8 \mathrm{O}, \mathrm{CHCl} 3, \mathrm{C} 2 \mathrm{H} 2 \mathrm{Cl} 2, \mathrm{C} 3 \mathrm{H} 6 \mathrm{O}$, $\mathrm{C} 3 \mathrm{H} 7 \mathrm{NO}, \mathrm{C} 2 \mathrm{HCl} 3, \mathrm{~N} 2 \mathrm{H} 4,(\mathrm{C} 2 \mathrm{H} 5) 3 \mathrm{~N}, \mathrm{C} 6 \mathrm{H} 14$, etc.) with new and improved detection limits using electrospunnanofibrousmembranes as sensing structures. The types of prepared gas sensors mainly include acoustic wave, resistive, photoelectric, and optical gas sensors. Electrospunfibers with polyelectrolyte components, conducting polymer composites, and semiconductors are successfully applied as gas sensing interfaces with the fiber arrangement of single fiber, oriented fibers, or nonwoven membranes at room or elevated operating temperature.

\subsection{OXIDE SEMICONDUCTOR GAS SENSORS:}

Semiconductor gas sensors utilize porous polycrystalline resistors made of semiconducting oxides. Semiconductor gas sensors have been investigated extensively for the purpose of practical applications, such as gas leak detectors and environmental monitoring. Numerous kinds of gases are emitted from various sources into our living space, working space, or outdoors. Many of them are hazardous to human beings and the environment, like air pollutants, while some others can be used as measures to diagnose the state of their sources, like ethanol and acetone in the breath and flavor components of foods. Most of these gases are present at very low concentrations so that extremely good sensing characteristics are required for their monitoring. In order to realize such gas sensors, it seems imperative to establish the principles of sensor design on the basis of fundamental understandings of semiconductor gas sensors.

\subsubsection{WORKING MECHANISM:}

The process of gas sensing by a semiconductor device involves two key functions 
(i) recognition of a target gas through a gas-solid interaction which induces an electronic change of the oxide surface (receptor function) and

(ii) transduction of the surface phenomenon into an electrical resistance change of the sensor (transducer function).

It was proposed at relatively early stage that the receptor function is provided by the surface chemical properties of oxide grains to adsorb or react with the target gas. This understanding has been strengthened by the elucidation of oxygen adsorptive properties of oxides and the findings of remarkable sensitizing actions played by various foreign receptors introduced into the grains. On the other hand, findings of grain size effects on the sensor resistance and response as well as of the remarkable effects of several foreign receptors on the work function of oxides have contributed to establish the concept that a surface space charge layer formed on the oxide grains induces gas-dependent barriers for conduction electrons to cross the grain boundaries (transducer function). The relevance of gas response to the porous structure of gas sensing bodies has been analyzed based on a diffusion-reaction equation]. The penetration depth of the target gas into the gas sensing bodies (utility factor) can predict how the gas response depends on the chemical and physical properties of target gas and the microporous structure of sensing bodies. These key factors, i.e., receptor function, transducer function, and utility factor, can be changed often markedly with changes in base semiconducting oxides, foreign materials introduced, and high-order structure of the sensing bodies.

\subsubsection{SENSING MECHANISM:}

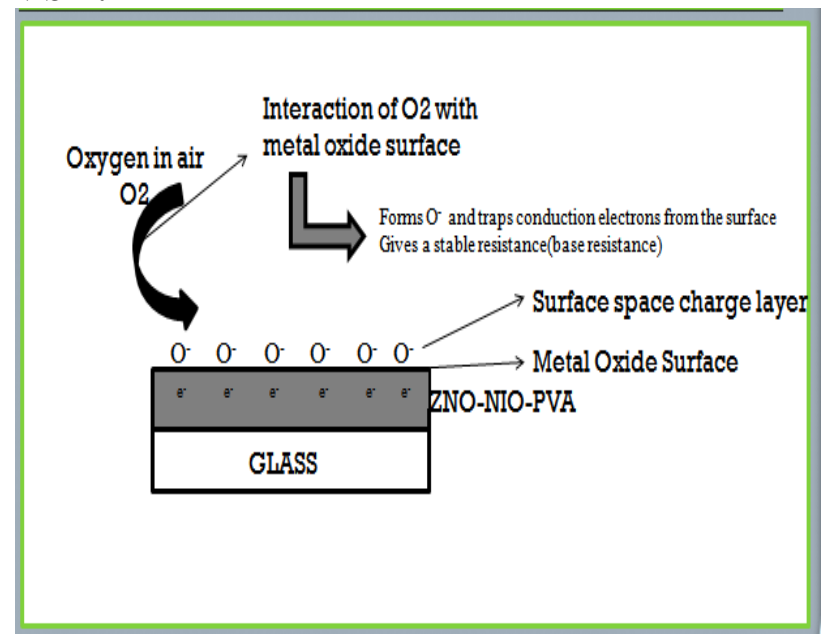

Fig 4.1 Gas Sensing Mechanism of Metal Oxides

\subsection{PROPERTIES}

The important property for a base semiconductor is chemical and thermal stability under the sensor operating conductions. Surface chemical properties are also important in some cases, especially when the base semiconductor is utilized without additives. For example, WO3 has been used preferably for sensing NO2 and NH3: However, the surface properties are of relatively minor importance because the surface can be modified by depositing foreign materials.

\subsubsection{SURFACE CHEMICAL PROPERTIES: (NATIVE RECEPTORS)}

Generally speaking, n-type oxides have far smaller amounts of adsorbed oxygen on the surface than $p$ type oxides. Nevertheless, oxygen adsorption is distinctly observed for most of the n-type oxides. Moleculartype adsorbates, $\mathrm{O}_{2}(\mathrm{a} 1)$ and $\mathrm{O}_{2}^{-}(\mathrm{a} 2)$ and a dissociative type one, $\mathrm{O}^{-}(\mathrm{b})$; are discerned to desorb depending on the adsorption conditions, in addition to surface (lattice) oxygen, $\mathrm{O}^{2-}(\mathrm{c})$ which desorbs in the temperature range above $550 \mathrm{C}$. Since gas sensors are usually operated at $3008 \mathrm{C}$ and above, the species $\mathrm{O}^{-}(\mathrm{b})$ is more important than the other oxygen adsorbates. For a target gas having a tendency to adsorb strongly like $\mathrm{NO}_{2}$ or $\mathrm{O}_{3}$; the surface adsorption sites simply act as receptors. For inflammable gases involving $\mathrm{N}$, $\mathrm{O}$, or functional groups, acidic or basic oxides such as WO3 or In2O3 often provide better sensing characteristics than $\mathrm{SnO} 2$. In most of these cases, the surface acid-base properties play important roles. As described later, however, more effective foreign receptors are often introduced on the oxide surface to replace these native receptors.

\subsubsection{SURFACE MODIFIERS:(FOREIGN RECEPTORS)}

For the detection of inflammable gases, the gas-solid interaction involved in the receptor function is the catalytic oxidation of the target gas over the grain surface. If the oxide has a bare surface, surface oxygen 
(adsorbed or lattice oxygen) is utilized for the oxidation reaction, and the resulting decrease of surface oxygen at steady state induces a change in surface space charge layer, which in turn is transduced into a change in electrical resistance as mentioned above. In many cases, however, the bare oxide surface is not active enough, so that various kinds of foreign materials are deposited on the surface. Actually it was the finding of sensitizing actions by noble metals like Pd that contributed much to establishing inflammable gas sensors. There are also other types of sensitization, as described below.

Two types of interactions between metal additive and oxide semiconductor have been conceived. In the first type, an inflammable gas (H2) is activated by the metal additive and the activated fragments $(\mathrm{H})$ of the gas are spilt-over to the semiconductor surface to react with the adsorbed oxygen. The metal additive thus facilitates chemical reaction of the gas on the semiconductor. This type of promoting effect is called chemical sensitization. The spillover phenomenon is known to occur in the catalysis of Pt loaded oxides so that this type sensitization has been assumed for Pt-loaded sensors. In the second type (electronic sensitization), on the other hand, there is no such mass transfer between the additive and the oxide. Instead, the additive in the oxidized state acts as a strong acceptor of electrons from the oxide, inducing a surface space charge layer which is strongly depletive of electrons in the oxide near the interface. When the additive is reduced on contact with the target gas, it relaxes the space charge layer by giving back electrons to the oxide.

\subsubsection{MICROSTRUCTURE-DEPENDENT CHARACTERISTICS:}

The above discussion focuses on how oxide grains or grain boundaries respond to a target gas. Each grain or grain boundary has been assumed as if it were located in an open space. However, this is actually not the case because a large number of oxide grains stack together in the sensing body. The target gas (inflammable gas) diffuses in the sensing body through pores, while it is consumed by the reaction with the surface oxygen. Upon exposure to an inflammable gas at a fixed concentration, the target gas concentration decreases on going inside the sensing body. The grains located deep inside may remain intact or inaccessible for the gas under certain conditions, leading to reduced gas response. This means a decrease in utility of the sensing body or a decrease in accessibility of the target gas. To discuss this phenomenon, one needs to know the concentration profile of the target gas inside the sensing body [6]. It is known that the mechanism of gas diffusion through a porous material depends on the size of the pores involved. In the range of pore size between 2 and $50 \mathrm{~nm}$ in radius (conventionally called mesopores), Knudsen diffusion prevails, while surface diffusion or molecular diffusion does in the ranges of pore size below $2 \mathrm{~nm}$ (micropores) or above $50 \mathrm{~nm}$ (macropores), respectively. The gas sensors conventionally prepared possess pores of various sizes, making the analysis difficult. For this purpose, one needs to have gas sensors well defined in grain size, pore size, and thickness (gas diffusion depth).

\subsubsection{EXTENSION TO NON-UNIFORM SENSING BODIES}

The sensing body should be porous enough and thin enough in order to obtain a high gas response. This is particularly important for the target gas with large molecular weight or large reactivity. As the porosity tends to increase with an increase in grain size, higher response can be expected with larger oxide grains, except for the range of grain size smaller than twice the thickness of space charge layer. This is just opposite to what has often been assumed in the literature. The method and condition of oxide powder processing are thus very important for the control of the microporous structure of sensing bodies. Thick films and sintered blocks possess far more complex microporous structure than the spin-coated thin films described above. Nevertheless, almost the same conclusions are likely to hold for these cases, if the film thickness is replaced by the secondary particle size. In these sensing bodies, oxide grains (primary particle) gather together to form secondary particles of 1-10 $\mathrm{mm}$ in diameter, leaving macropores among them. Gas diffusion through macropores (molecular diffusion) is rapid so that the target gas can reach the surface of each secondary particle very easily. In addition, gas diffusion into secondary particles is essentially very similar to that into thin films because the mesopore structure should be almost the same. Since the sizes of secondary particles are usually far larger than the thicknesses of thin films, the accessibility of gas molecules inside secondary particles (utility) becomes far more limited than the case of thin films. Obviously, a decrease in secondary particle size as well as an increase in the size of the mesopores are the way to obtain a higher gas response for these sensors.

\subsection{MATERIALS AND METHODS:}

\section{Synthesis Procedure:}

$>$ All the chemical reagents used in our experiments were of analytical grade and were used as received without further purification.

$>$ Zinc Acetate, Nickel Acetate and Polyvinyl alcohol(powder) are AR Grade chemicals and used as starting material for the preparation of nanofibers. 


\subsection{EXPERIMENTAL:}

\subsubsection{SOL PROCESSING:}

The nanofibers are prepared by electrospinning method. PVA (MW 150,000) aqueous solution (15wt\%) was first prepared by dissolving $3 \mathrm{~g}$ PVA powder in $20 \mathrm{ml}$ distilled water with stirring for $2 \mathrm{~h}$ at $90 \mathrm{C}$, then cooled to room temperature and kept stirring for $12 \mathrm{~h}$.

Initially, 1 molar of zinc acetate dehydrate was dissolved in $10 \mathrm{ml}$ distilled water to prepare Zinc Oxide nanoparticles.

Similarly 1 molar of nickel acetate tetrahydrate was dissolved in $10 \mathrm{ml}$ distilled water to prepare Nickel Oxide nanoparticles.

We took $\mathrm{ZnO}$ and $\mathrm{NiO}$ as 1:1 molar ratio to the polymer solution and stirred for some time at slow speed. A green transparent sol solution was prepared.

\subsubsection{ELECTROSPINNING PROCESS:}

The mixed polymer sol solution is loaded into the syringe and placed into the syringe pump.

The electrodes are connected to the needle and the collector.

The spinneret served as one electrode and the iron drum collector covered with aluminium foil served as another electrode.

A high voltage was applied to the needle and the polymer solution is charged.

This high voltage extracts the sol from the needle and forms a cone called Taylor Cone.

Thedense fibers will form after the formation of cone.

The fibers thus formed were collected on the glass substrate for sensing applications.

The samples are characterized by SEM, EDAX and XRD.

\subsubsection{PARAMETERS CONSIDERED:}

Distance between the needle and the collector is $18 \mathrm{~cm}$.

Voltage $-20 \mathrm{KV}$

Flow rate $-0.5 \mathrm{ml} / \mathrm{hr}$.

Rotation speed- 700-800 rpm.

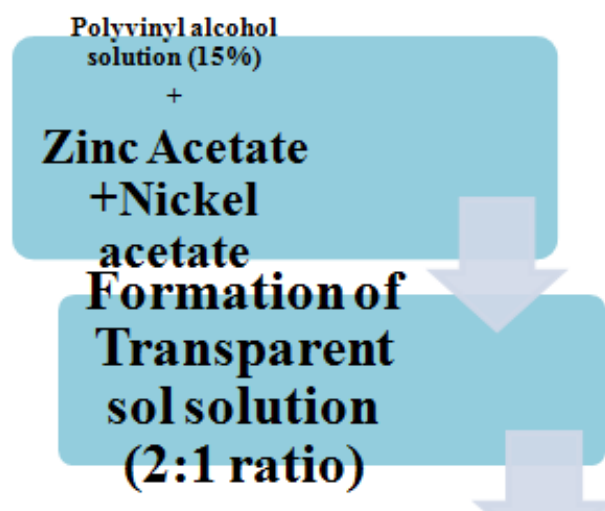

\section{Electrospinni \\ ng}

\section{Fiber}

Formation 
In this paper, $\mathrm{NiO} / \mathrm{ZnOnanocomposite} \mathrm{combined} \mathrm{with} \mathrm{Polyvinyl} \mathrm{Alcohol(PVA)} \mathrm{polymer} \mathrm{has} \mathrm{been} \mathrm{coated} \mathrm{on}$ glass substrate for the gas sensor application.

The gas sensing studies of Ammonia, Formaldehyde and $\mathrm{CH}_{4}$ were done

3.1 SEM:

III. Results And Discussions:

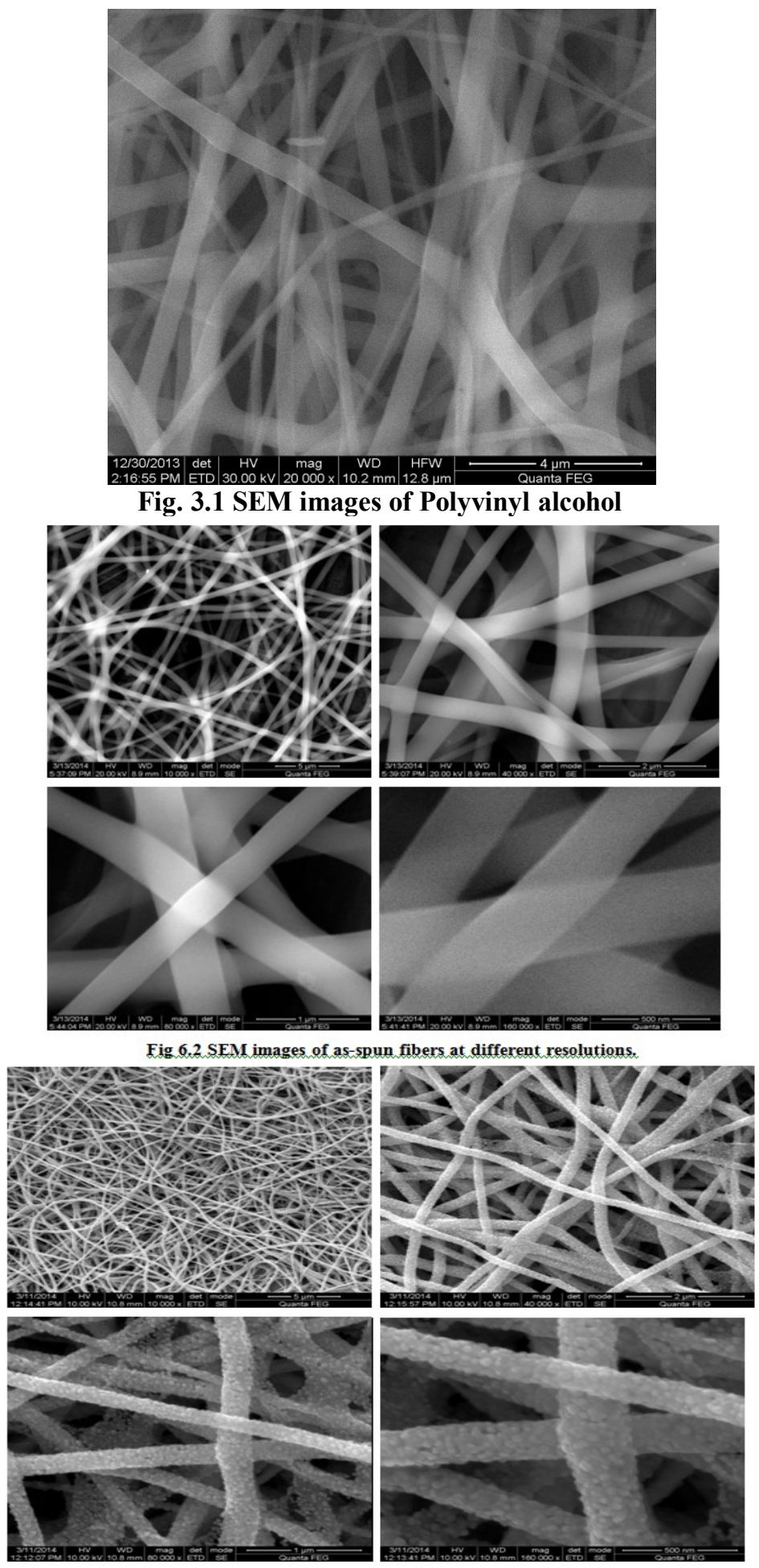

Fig 6.3 SEM images of $500^{\circ} \mathrm{C}$ annealed fibers

The Scanning electron microscope was used to analyze the surface morphology of the fibers. Fig 6.1 shows the SEM images of polyvinyl alcohol(PVA) and it confirms that PVA can be able to form the fibers at nanorange. It demonstrates that the smooth surface was formed. Fig. 6.2 (a, b, c and d) show SEM images for a 
sample of NiO-ZnO-PVA nanofibers at different magnification with a diameter of $450 \mathrm{~nm}$. Fig 6.3 (a, b, c and d) shoes the SEM images for a sample of $500^{\circ} \mathrm{C}$ annealed $\mathrm{ZnO}-\mathrm{NiOnanofibers.} \mathrm{It} \mathrm{can} \mathrm{be} \mathrm{seen} \mathrm{that} \mathrm{the} \mathrm{fbers} \mathrm{are}$ quite uniform with a diameter of about $250 \mathrm{~nm}$, and the porous structure can be observed as a result of the decomposition of PVA during annealing.

\subsection{ENERGY DISPERSIVE X-RAY SPECTROSCOPY:}

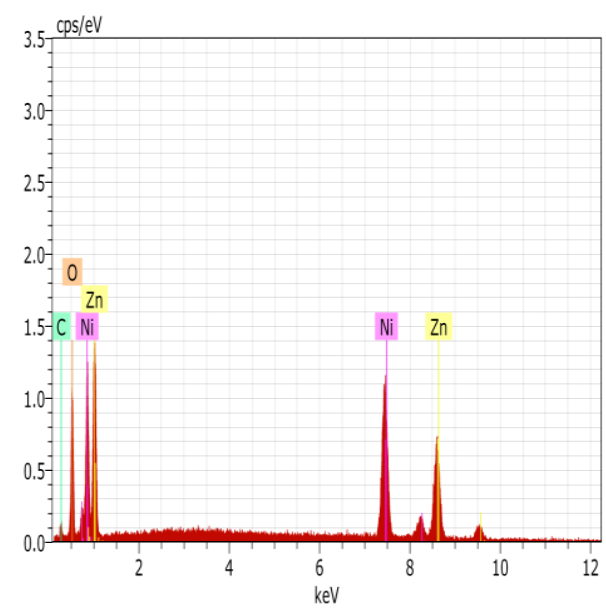

El AN Series unn. C norm. C Atom. C Error (1 Sigma)

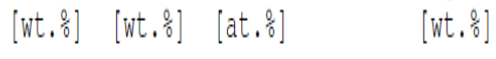

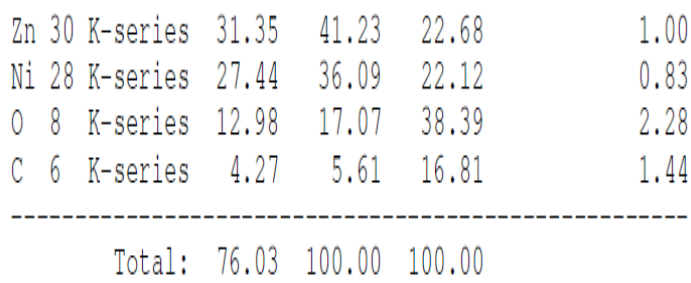

Fig 3.4 EDX spectra of $500^{\circ} \mathrm{C}$ annealed $\mathrm{ZnO} / \mathrm{NiOnanofibers}$

The EDX spectrum shown in Fig.6.4 indicates that the atomic ratio of $\mathrm{Ni}$ to $\mathrm{Zn}$ in the resultant NiOZnOnanofibers is around $1: 1$, which is consistent with the composition of the precursor solution. This figure confirms the presence of the chemical composition in the sample.

6.3 XRD:

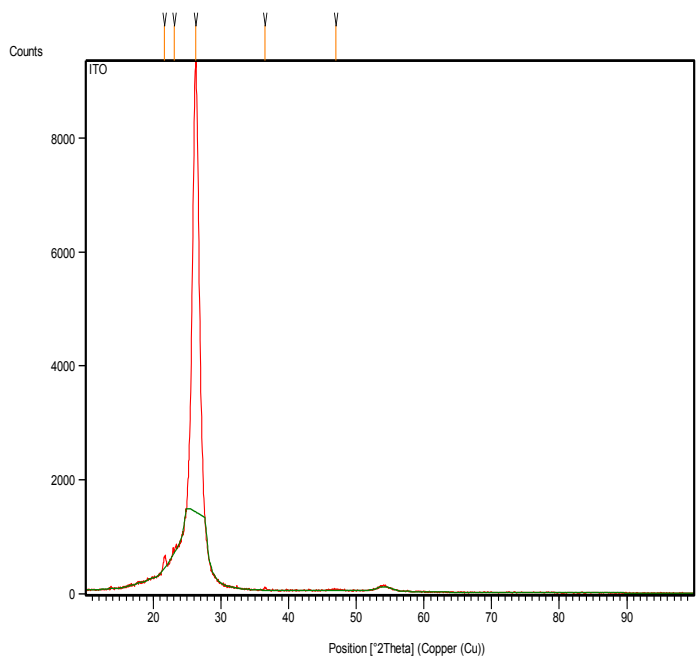

Fig.3.5 XRD image of as-spun PVA/ZnO/NiOnanocomposite fibers 
From Fig 6.5, The XRD result for unannealed PVA/ZnO/NiO composite fibers shows that the polymer count has larger than the composites. This is because that the ratio of polymer to the nanocomposite is $2: 1$. So, this result shows that it has less count for the nanocomposite material.

X-ray powder diffraction measurements were carried out to substantiate the structural and phase composition of the samples. Fig. 6.6 b) shows typical XRD patterns of the resultant NiO-ZnOnanofibers. The main characteristic peaks of NiO from JCPDS card no. 65-2901 and ZnO from JCPDS card no. 36-1451 are also given for comparison. The formation of cubic crystalline $\mathrm{NiO}$ in the hybrid is revealed by the diffraction peaks centered at $37.25^{\circ}, 43.35^{\circ}$ and $62.89^{\circ}$ corresponding to the (111), (200) and (220) crystal planes, respectively. The diffraction peaks at values of $31.72^{\circ}, 36.27^{\circ}$ and $62.75^{\circ}$ are ascribed to the wurtzite crystal structure of $\mathrm{ZnO}$, which correspond to the (100), (101) and (110) crystal planes,respectively. From Fig 6.6a, The XRD measurement demonstrates that thehybrid is composed of crystalline $\mathrm{NiO}$ and $\mathrm{ZnO}$, which agreeswith the results shown in Fig. 6.6b. Furthermore, thediffraction peaks of $\mathrm{NiO}$ and $\mathrm{ZnO}$ are sharp and intense,implying the high crystallinity of the nanofibers.

\subsection{UV-VISIBLE SPECTROMETER:}

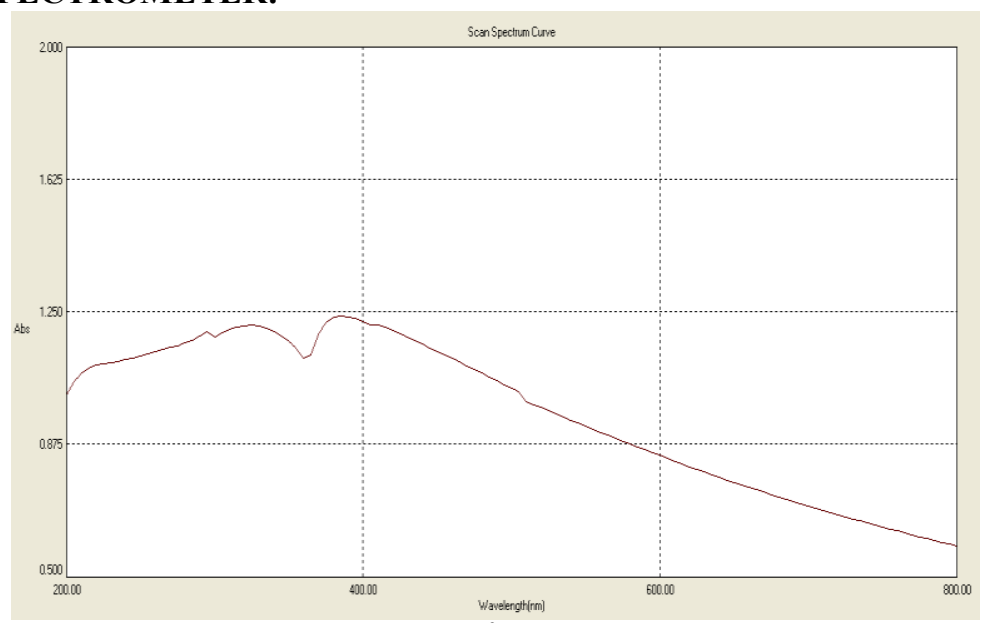

Fig 3.7 UV-VIS of $500^{\circ} \mathrm{C}$ ZnO-NiOnanofibers

\begin{tabular}{|c|c|c|}
\hline & Wavelength(nm) & Absorption \\
\hline 1 & 385 & 1.240 \\
\hline 2 & 325 & 1.213 \\
\hline
\end{tabular}

3.5 SENSING SETUP:

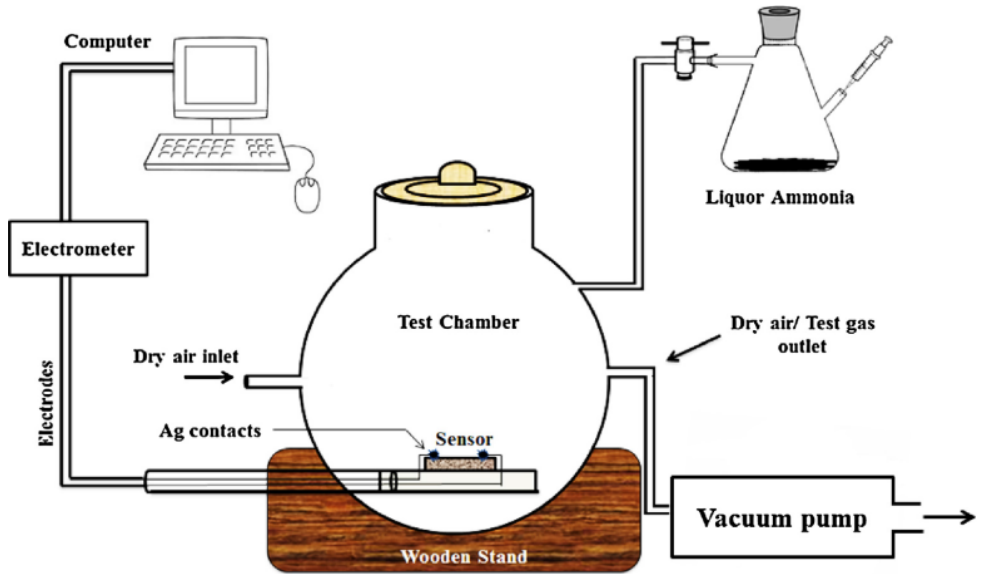

\subsubsection{SENSOR TEST:}

Fig 6.8 SENSING SETUP

Here fiber coated glass substrate is taken for sensor testing.

The sample is dried at $60 \mathrm{C}$ for 2 hours and then taken for sensor testing.

The volatile gases such as Formaldehyde $(\mathrm{HCHO})$, Ammonia $\left(\mathrm{NH}_{3}\right)$ and Methane $\left(\mathrm{CH}_{4}\right)$ are used for testing the sample.

First the silver paste is applied like a little drop on the sample and then heated in oven for $100^{\circ} \mathrm{C}$ 
The sample is connected to the resistance meter via two copper wires through silver paste.

The sample is kept in the atmospheric air to check the base resistance.

Then the sample is kept inside the chamber and closed it.

The target gas is allowed to pass inside the chamber.

The resistance meter records the resistance value of the sample when target gas flows inside the chamber.

3.5.2 ELECTRO METER/HIGH RESISTANCE METER: (6517 Hi-R METER)

This high resistance meter is used to make

Current,

Voltage and

Resistance measurement values of sensing device.

\subsubsection{SENSITIVITY FORMULA:}

where $\mathrm{R}_{\mathrm{a}}$ - Resistance in air $\mathbf{S}=\mathbf{R}_{\mathrm{a}}-\mathbf{R}_{\mathrm{g}}$ $\mathrm{R}_{\mathrm{g}}-$ Resistance in gas

\subsection{SENSING GASES:}

1. AMMONIA $\left(\mathrm{NH}_{3}\right)$ :

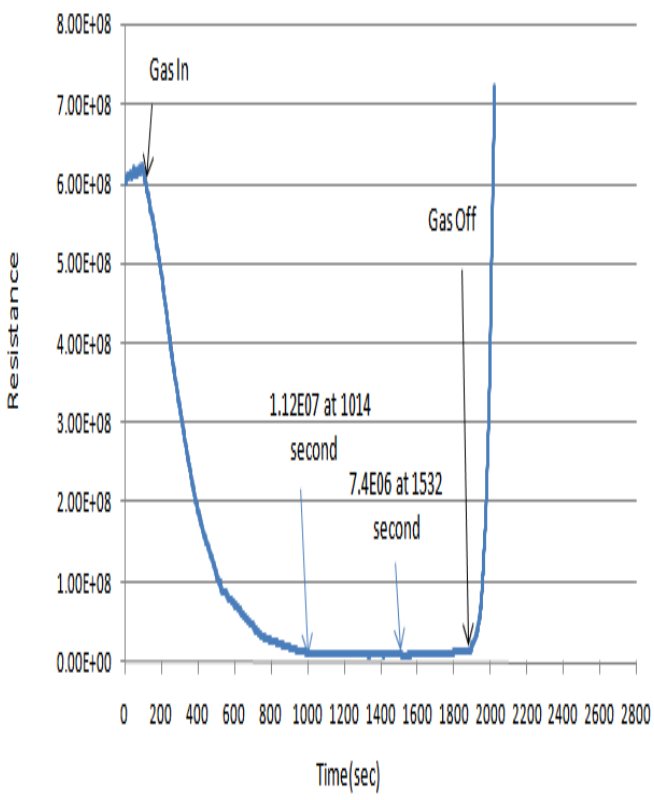




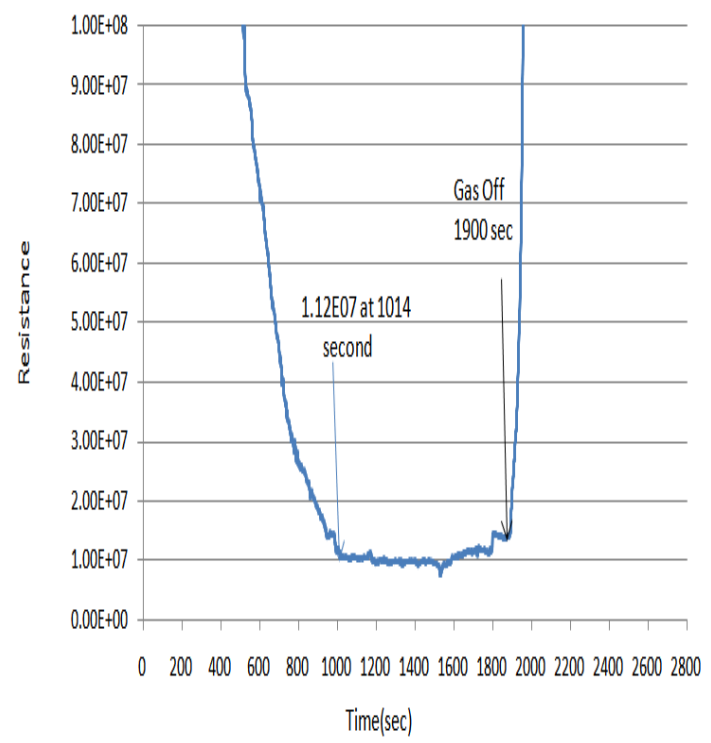

Fig 3.9 Resistance response of as-spun PVA-ZnO-NiOnanofibers towards ammonia gas $2 \mathrm{NH}_{3}+5 \mathrm{O}^{-}(\mathrm{ad}) \rightarrow 2 \mathrm{NO}+3 \mathrm{H}_{2} \mathrm{O}+5 \mathrm{e}^{-}$

The base resistance value is 6.1E8. After the base resistance is taken, the gas is passed at $150^{\text {th }}$ second and the curve gradually decreases from E8 to E7 and gets constant after 1500 seconds. This indicates that the sample has sensitivity for ammonia gas. Finally the vacuum pump is swiched ON to release the gases present inside the chamber and the resistance curve increases. PVA restricts some amount of gas sensitivity to the sample, still it shows good sensitivity of $98 \%$ for ammonia gas.

\section{FORMALDEHYDE:}

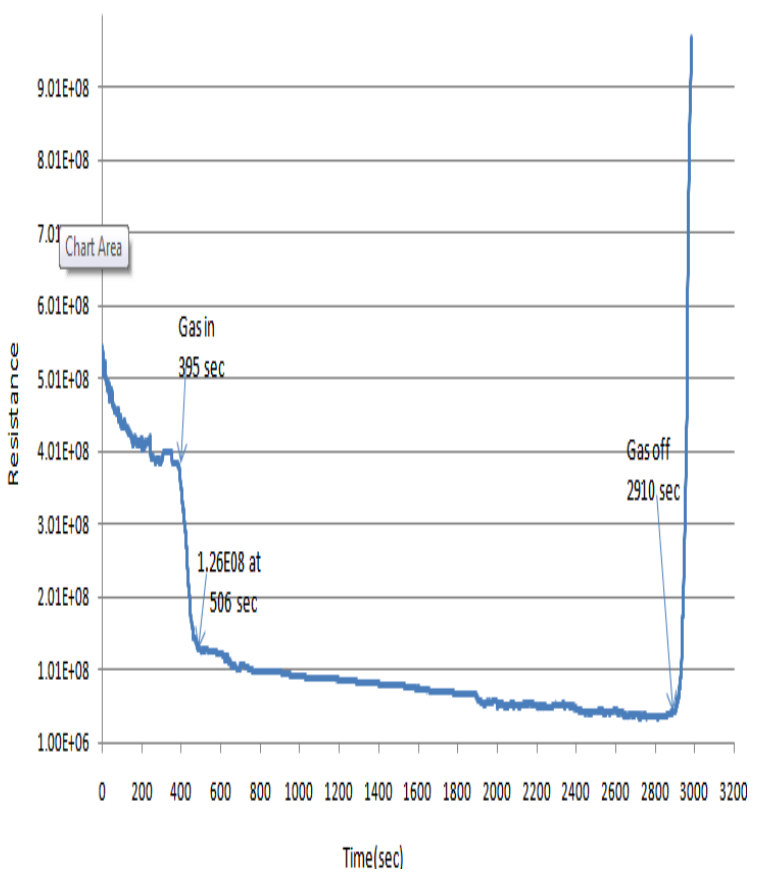

Fig 3.10 Resistance response of as-spun nanofibers towards formaldehyde gas

The above figure shows that the base (or atmospheric) resistance took for 400 seconds and the average base resistance value is $4.5 \mathrm{E} 8$. Then the chamber is opened and the formaldehyde (liquid form) is allowed to pass inside the chamber close to the sample and the chamber is closed. Then the resistance curve decreases when the gas passes to the sample. The sensor testing is continued for 2000 seconds. The curve decreases from 
E9 to E7 and then it became constant. It indicates that the sample senses the formaldehyde gas. Because of the presence of some amount of polymer in the sample, it restricts the gas sensing. Finally the vacuum pump is swiched ON to release the gases present inside the chamber and the curve increases. The sensitivity is $73 \%$

\section{METHANE:}
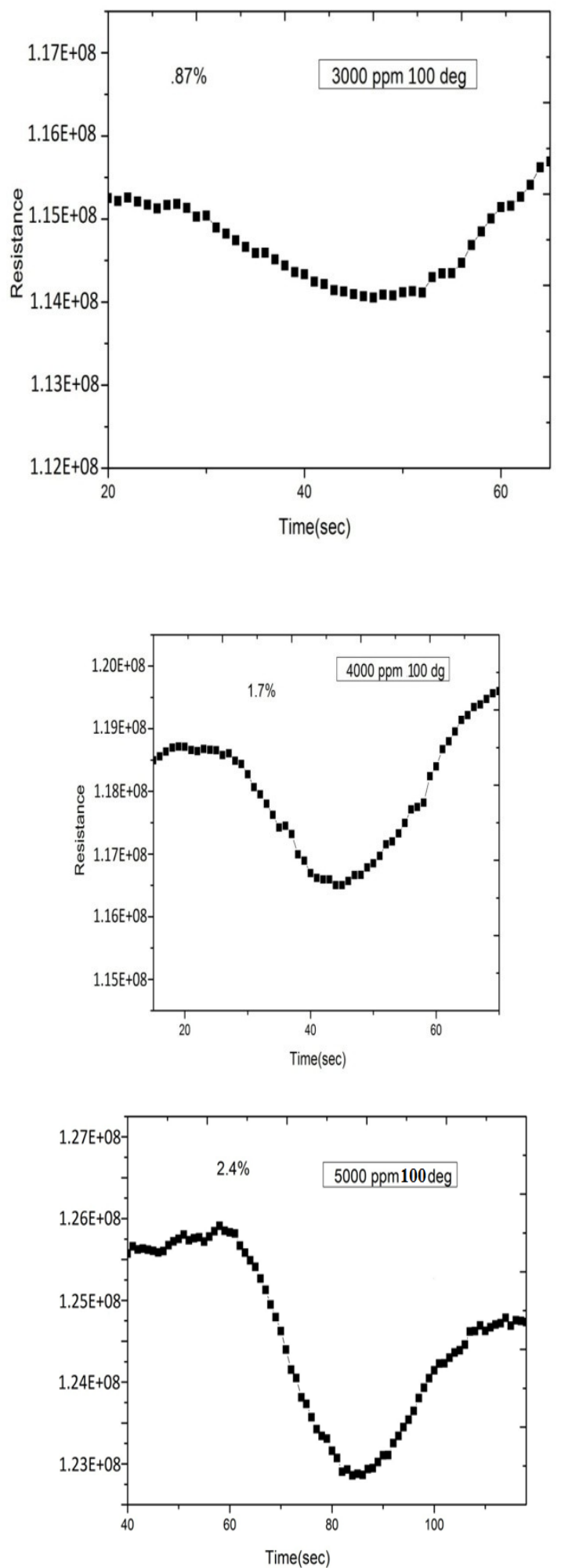


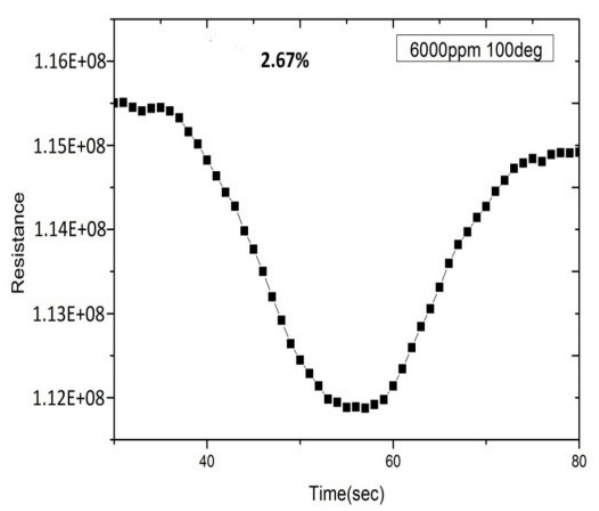

Fig 3.11 (a, b, c and d) Resistance Response towards methane gas at different ppm

$$
\mathrm{CH}_{4}+2 \mathrm{O}_{2}^{-}=\mathrm{CO}_{2}+2 \mathrm{H}_{2} \mathrm{O}+4 \mathrm{e}^{-}
$$

From the above figure 6.11 , it shows the change in resistance value of the sample heated at $100^{\circ} \mathrm{C}$ for methane gas at different ppm . From 6.11 ( $\mathrm{a}, \mathrm{b}, \mathrm{c}$ and d), itshows different gas sensitivity. At $3000 \mathrm{ppm}$, it shows poor sensing and has sensitivity of $0.87 \%$. At $4000 \mathrm{ppm}$, it has sensitivity of $1.7 \%$. For $5000 \mathrm{ppm}$, it has sensitivity of $2.4 \%$. At $6000 \mathrm{ppm}$, it shows good sensing and has $2.67 \%$ sensitivity. From this, we can understand that when the ppm level increases, sensitivity also increases.

\section{REASONS FOR NOT SENSING AT ROOM TEMPERATURE:}

1. Ammonia follows $\mathrm{sp}^{3}$ hybridization and it has extra pair of electrons. This electron plays a major role in sensing because this paired electron from ammonia and formaldehyde passes to the sample at room temperature. There is no need to give external energy. But in methane, it also follows $\mathrm{sp}^{3}$ hybridization but has no extra pair of electrons. So, the external energy such as heat energy required to break the bond to produce electrons.

Ammonia $\left(\mathrm{NH}_{3}\right)$ : Nitrogen Atomic number: $7 \quad\left(1 \mathrm{~s}^{2} 2 \mathrm{~s}^{2} 2 \mathrm{p}^{3}\right)$

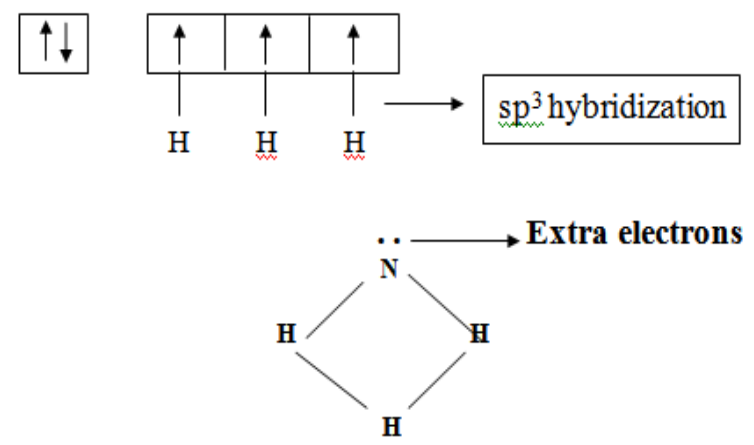

Methane ( $\left.\mathrm{CH}_{4}\right)$ : Carbon Atomic number: $6 \quad\left(\mathbf{l s}^{2} 2 \mathrm{~s}^{2} \mathbf{2 p} 2\right)$

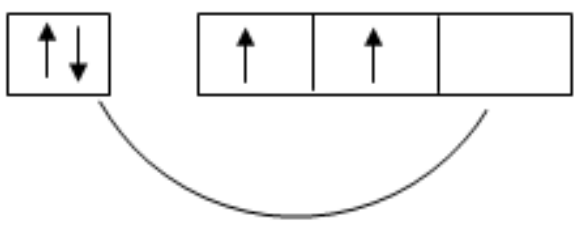




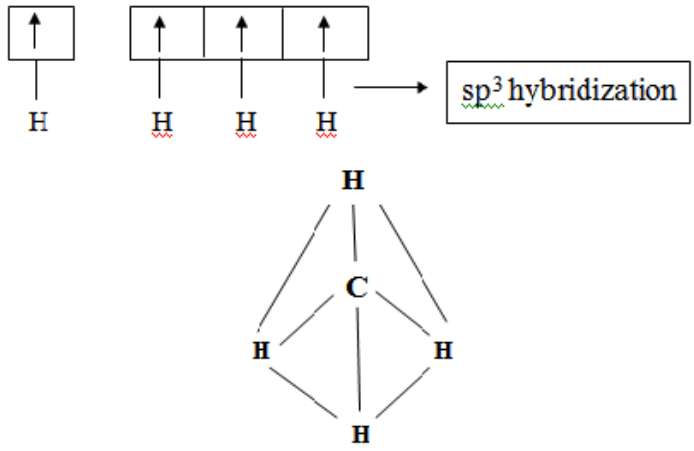

2. Ammonia and formaldehyde shows sensing at low ppm but methane doesn't. Why methane has low sensing at high temperature? If the oxide has a bare surface, surface oxygen (adsorbed or lattice oxygen) is utilized for the oxidation reaction, and the resulting decrease of surface oxygen at steady state induces a change in surface space charge layer, which in turn is transduced into a change in electrical resistance. In many cases (eg: $\mathrm{CH}_{4}$, $\mathrm{H}_{2} \mathrm{~S}$ ), however, the bare oxide surface is not active enough, so that various kinds of foreign materials are deposited on the surface. Actually it was the finding of sensitizing actions by noble metals like Pd that contributed much to establishing inflammable gas sensors.

\section{Conclusion:}

The main aim of this project is to use the sensors at room temperature. The gases such as ammonia and formaldehyde shows good response at room temperature for as-spun fibers but methane gas doesn't show any response at room temperature.

\begin{tabular}{|l|c|c|c|c|}
\hline GAS & PPM & $\begin{array}{c}\text { ROOM } \\
\text { TEMPERATURE }\end{array}$ & $100 \mathrm{C}$ & SENSITIVITY \% \\
\hline AMMONIA & 50 & $\checkmark$ & & 98 \\
\hline FORMALDEHYDE & 50 & $\checkmark$ & & 73 \\
\hline CH4 & 3000 & & $\checkmark$ & 0.87 \\
\hline & 4000 & & $\checkmark$ & 1.7 \\
\hline & 5000 & & $\checkmark$ & 2.4 \\
\hline & 6000 & & $\checkmark$ & 2.67 \\
\hline
\end{tabular}

Table 6.7Comparision of sensitivity to different gases

The above table shows the comparision of sensing of different gases. From the table we can find that the ammonia has good sensitivity. Further, we have to take the sensor test for $500^{\circ} \mathrm{C}$ annealed fibers and make the comparision of as-spun $\mathrm{ZnO}-\mathrm{NiOnanofibers}$ and the annealed $\mathrm{ZnO}-\mathrm{NiOnanofibers.}$

\section{References}

[1] Electrospinning of Nanomaterials and Applications in Electronic Components and Devices Jianjun Miao, Minoru Miyauchi, Trevor J. Simmons, Jonathan S. Dordick, and Robert J. Linhardt

[2] R. Jiri, P. Marek, V. Vladimir, Aligned nano fiber deposition onto a apatterened rotating drum collector by electrospinning, Brno, Czech Republic, EU, (2011)

[3] S. N. Reznik, , A. L. Yarin, , A. Theron, E. Zussman, Transient and steady shapes ofdroplets attached to a surface in a strong electric field. Journal of Fluid Mechanics, 516 (2004), 349-377.

[4] Ondarcuhu T, Joachim C. Drawing a single nanofibre over hundreds of microns. EurophysLett 1998;42(2):21520.

[5] Feng L, Li S, Li H, Zhai J, Song Y, Jiang L, et al. Super-Hydrophobic Surface of Aligned PolyacrylonitrileNanofibers. AngewChemInt Ed 2002;41(7):1221-3.

[6] Ma PX, Zhang R. Synthetic nano-scale fibrous extracellular matrix. J Biomed Mat Res 1999;46:60-72.

[7] Liu GJ, Ding JF, Qiao LJ, Guo A, Dymov BP, Gleeson JT, et al. Polystyrene-block-poly (2-cinnamoylethyl methacrylate) nanofibers-Preparation, characterization, and liquid crystalline properties. Chem-A European J 1999;5:2740-9.

[8] Deitzel JM, Kleinmeyer J, Hirvonen JK, BeckTNC. Controlled deposition of electrospunpoly(ethylene oxide) fibers. Polymer 2001;42:8163-70.

[9] Zheng-Ming Huanga, Y.-Z. Zhangb, M. Kotakic, S. Ramakrishna. A review on polymer nanofibers by electrospinningand their applications in nanocomposites. Composites Science and Technology 63 (2003) 2223-2253

[10] Jianjun Miao, Minoru Miyauchi4, Trevor J. Simmons, Jonathan S. Dordick, and Robert J. Linhardt. Electrospinning of Nanomaterialsand Applications inElectronic Components and Devices.Journal of Nanoscience and Nanotechnology. Vol. 10, 55075519,2010 